\title{
Clustering of the morphological components of perinatal telencephalic leucoencephalopathy
}

\author{
ALAN LEVITON AND FLOYD H. GILLES \\ From the Department of Pathology (Neuropathology), The Children's Hospital Medical Center, and the \\ Department of Neurology-Neuropathology, Harvard Medical School, Boston, Massachusetts, U.S.A.
}

SUMMARY The data upon which the original report of perinatal telencephalicleucoencephalopathy was based have been examined for clustering of the four criteria of neonatal white matter damage. Three clusters have been identified: (1) acutely damaged glia with amphophilic globules, (2) hypertrophic astrocytes and amphophilic globules but without necrotic foci, and (3) hypertrophic astrocytes and amphophilic globules with necrotic foci. The original report of perinatal telencephalic leucoencephalopathy therefore probably included two entities. One was characterized by acutely damaged glia and amphophilic globules and the other by hypertrophic astrocytes and amphophilic globules. The two entities do not occur together significantly more frequently than would be expected on the basis of the independent occurrence of each.

Those abnormalities frequently seen in neonatal telencephalic white matter and considered evidence of white matter damage have recently been grouped under the heading 'perinatal telencephalic leucoencephalopathy' (PTL) (Gilles and Murphy, 1969). These abnormalities are hypertrophic astrocytes (HA), necrotic foci (NF), acutely damaged glia (ADG), and amphophilic globules (GL). By definition, the diagnosis of PTL has been confined to infants free of diseases considered neurotoxic.

It is possible that each criterion of white matter damage, or combination of criteria may not have the same clinical or morphological significance as other criteria occurring singly or in combination. With this in mind, the data upon which the original report of PTL was based have been examined for clustering of criteria of white matter damage.

\section{METHODS}

The population consisted of all infants with post mortem examinations at Children's Hospital Medical Center of Boston during the interval 1 January 1965 to 31 December 1967, who died between the ages of 6 gestational months and 4 postnatal months with diseases not known to damage the central nervous system. Infants were therefore excluded if they had any of the following conditions: meningitis, rubella, subdural haematoma, embolic encephalopathy, massive matrix haemorrhage with rupture into the telencephalon, intracranial tumour, hypoglycaemia, phenylketonuria, and hyperbilirubinaemia.
Of the 196 infants on whom the original report of PTL was based, 192 had sufficient information for epidemion logical studies. These 192 infants form the basis of thip study. The four infants excluded from analysis were originally classified as 'controls'.

The procedure for preparation of material for neuro pathological study has been detailed elsewhere (Gille and Murphy, 1969). After examination of the slides by two neuropathologists, the presence or absence of $\mathrm{HA}$, GL, ADG, and NF was tabulated for each infant. The two neuropathologists agreed fully in 185 cases and one neuropathologist was able to convince the other of an oversight in the remaining seven cases.

The entire study population of 192 infants was divided into exhaustive and mutually exclusive subsets defined by morphological abnormalities of telencephalic white matter. The Boolean algebra symbol of intersection, $n$ (cap) is replaced here by - (dot). Use of the dot means that both the criteria to the right and to the left of the symbol are satisfied. The subset HA.ADG therefore includes all infants with both HA and ADG. The absence of a characteristic is represented by a bar over the characteristic-for example, $\overline{\mathrm{HA}}$. The subset $\overline{\mathrm{HA}} \cdot$ ADG therefore includes only infants who do not have HA but do have ADG. Since four characteristics were used to define the population, a statement about the presence or absence of each characteristic formed the definition of each subset (Table 1).

The null hypothesis for the following statistical studies is: the occurrence of each white matter abnormality is independent of the occurrence of any other white matter abnormality. Under this hypothesis the occurrence of a combination of criteria is the product of the probabilities of each abnormality multiplied by the population at risk 
T A B L E 1

TABULATION OF NUMBER OF INFANTS IN EACH OF 16 SUBSETS

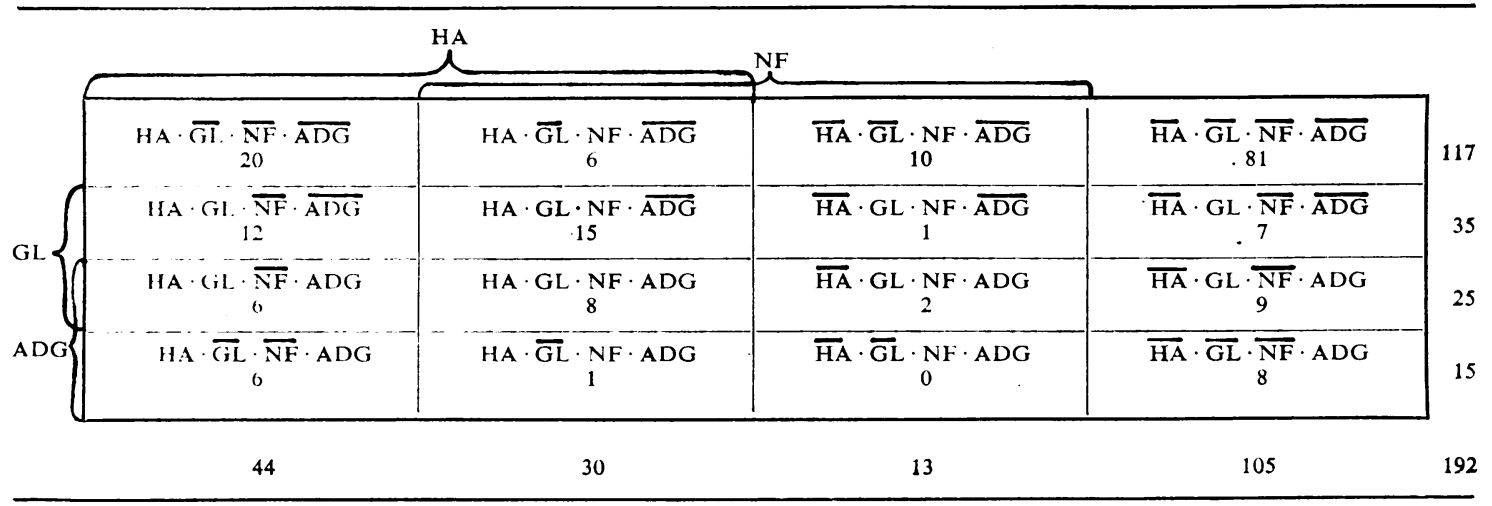

(Schor, 1968). An illustration of this follows. If in a population of 200 brains, abnormality $A$ is seen in 20 brains (probability of $A=\frac{20}{200}=0 \cdot 1$ ) and abnormality $B$ is seen in 40 brains (probability of $B=\frac{40}{200}=0 \cdot 2$ ), then $A$ and B should occur together $(0 \cdot 1)(0 \cdot 2)(200)$ or a total of only four times. This procedure was employed in calculating expected occurrences for Table 2 . The $95 \%$ and $99 \%$ confidence limits of expected occurrences of combinations of abnormalities have been interpolated from Documenta Geigy Scientific Tables (Diem, 1962).

A somewhat different approach was necessary to evaluate the association of two abnormalities without the confounding contribution of a third abnormality. Expected occurrences of combinations of two morphological abnormalities in the population devoid of the third abnormality were calculated in a manner similar to that employed for Table 2 with the exception that all brains with the third abnormality were totally eliminated from consideration. This procedure was employed in calculating expected occurrences for Table 3.

If abnormality $\mathrm{C}$ is seen in 50 brains (probability of $\mathrm{C}=$ $\left.\frac{50}{200}=0.25\right)$, then $\mathrm{A}, \mathrm{B}$, and $\mathrm{C}$ should occur together $(0 \cdot 1)(0 \cdot 2)(0 \cdot 25)(200)$ or a total of one time. On the other hand, if $A$ and $B$ have been shown not to be independent, an expected occurrence of $A, B$, and $C$ should not be based on the already disproved hypothesis of independence of $A$ and $B$, but rather on the number of brains observed with A and B together. This latter procedure was employed in calculating expected occurrences for Table 4.

\section{RESULTS}

The number of infants in each of the 16 subsets is tabulated in Table 1 . The observed occurrence of combinations of morphological abnormalities and
T A B L E 2

OBSERVED OCCURRENCE OF COMBINATIONS OF MORPHOLOGICAL ABNORMALITIES OF WHITE MATTER COMPARED WITH EXPECTED OCCURRENCE CALCULATED ON THE BASIS OF INDEPENDENCE OF MORPHOLOGICAL ABNORMALITIES

\begin{tabular}{|c|c|c|c|c|}
\hline \multirow[t]{2}{*}{ Combination } & \multirow[t]{2}{*}{$\begin{array}{c}\text { Observed } \\
\text { occurrence }\end{array}$} & \multirow[t]{2}{*}{$\begin{array}{c}\text { Expected } \\
\text { occurrence }\end{array}$} & \multicolumn{2}{|c|}{$\begin{array}{c}\text { Upper bound of expected } \\
\text { occurrence }\end{array}$} \\
\hline & & & $\begin{array}{l}95 \% \text { confidence } \\
\text { limit }\end{array}$ & $\begin{array}{l}99 \% \text { confidence } \\
\text { limit }\end{array}$ \\
\hline $\begin{array}{l}\text { ADG } \cdot \text { HA } \\
\text { ADG } \cdot \text { GL } \\
\text { ADG } \cdot \mathbf{N F} \\
\text { HA } \cdot \text { GL } \\
\text { HA } \cdot \mathbf{N F} \\
\text { GL } \cdot \mathbf{N F} \\
\text { HA } \cdot \text { GL } \cdot \mathbf{N F}\end{array}$ & $\begin{array}{l}21 \\
25 \\
11 \\
41 \\
30 \\
26 \\
23\end{array}$ & $\begin{array}{r}15 \cdot 4 \\
12 \cdot 5 \\
8 \cdot 9 \\
23 \cdot 1 \\
16 \cdot 6 \\
13 \cdot 4 \\
5 \cdot 2\end{array}$ & $\begin{array}{l}24 \cdot 9 \\
21 \cdot 4 \\
16 \cdot 8 \\
34 \cdot 0 \\
26 \cdot 4 \\
22 \cdot 4 \\
12 \cdot 4\end{array}$ & $\begin{array}{l}27 \cdot 8 \\
24 \cdot 1 \\
21 \cdot 0 \\
37 \cdot 3 \\
29 \cdot 4 \\
25 \cdot 3 \\
14 \cdot 6\end{array}$ \\
\hline
\end{tabular}

Expected occurrence $=$
$\left(\begin{array}{l}\text { fraction of entire } \\ \text { study population } \\ \text { with abnormality } \\ \text { A }\end{array}\right)\left(\begin{array}{l}\text { fraction of entire } \\ \text { study population } \\ \text { with abnormality } \\ \text { B }\end{array}\right)\left(\begin{array}{l}\text { number of infants } \\ \text { in entire study } \\ \text { population }\end{array}\right)$

T A B L E 3

EXPECTED OCCURRENCE OF COMBINATIONS OF TWO MORPHOLOGICAL ABNORMALITIES OF WHITE MATTER CALCULATED ON BASIS OF INDEPENDENCE OF ABNORMALITIES IN THE POPULATION DEVOID OF THIRD ABNORMALITY COMPARED WITH OBSERVED OCCURRENCE IN THAT POPULATION

\begin{tabular}{|c|c|c|c|c|c|}
\hline \multirow[t]{2}{*}{$\begin{array}{l}\text { Com- } \\
\text { ination }\end{array}$} & \multirow{2}{*}{$\begin{array}{c}\text { Population } \\
\text { devoid of } \\
\text { brains } \\
\text { with } \\
\text { following } \\
\text { abnormality }\end{array}$} & \multirow{2}{*}{$\begin{array}{c}\text { Observed } \\
\text { occurrence } \\
\text { in this } \\
\text { population }\end{array}$} & \multirow{2}{*}{$\begin{array}{l}\text { Expected } \\
\text { occurrence }\end{array}$} & \multicolumn{2}{|c|}{$\begin{array}{c}\text { Upper bound of expected } \\
\text { occurrence }\end{array}$} \\
\hline & & & & $\begin{array}{l}95 \% \text { confi- } \\
\text { dence limit }\end{array}$ & $\begin{array}{l}99 \% \text { confi- } \\
\text { dence limit }\end{array}$ \\
\hline $\begin{array}{l}\mathrm{GL} \cdot \mathbf{N F} \\
\mathbf{H A} \cdot \mathbf{N F} \\
\mathbf{H A} \cdot \mathbf{G L}\end{array}$ & $\begin{array}{l}\text { HA } \\
\text { GL } \\
\text { NF }\end{array}$ & $\begin{array}{r}3 \\
7 \\
18\end{array}$ & $\begin{array}{l}2 \cdot 1 \\
4 \cdot 3 \\
10\end{array}$ & $\begin{array}{r}7 \cdot 1 \\
10 \cdot 5 \\
17 \cdot 8\end{array}$ & $\begin{array}{r}9 \cdot 0 \\
12 \cdot 7 \\
20 \cdot 3\end{array}$ \\
\hline
\end{tabular}


T A B L E 4

OBSERVED OCCURRENCE OF COMBINATIONS OF MORPHOLOGICAL ABNORMALITIES OF WHITE MATTER COMPARED WITH EXPECTED OCCURRENCE CALCULATED ON BASIS OF ADDITIONAL ABNORMALITY OCCURRING PROPORTIONATELY NO MORE FREQUENTLY IN ANY SAMPLE OF THE POPULATION THAN IN THE ENTIRE POPULATION

\begin{tabular}{|c|c|c|c|c|c|c|}
\hline \multirow{2}{*}{$\begin{array}{c}\text { Additional } \\
\text { abnormality }\end{array}$} & \multirow[t]{2}{*}{ Combination } & \multirow{2}{*}{$\begin{array}{c}\text { Observed } \\
\text { occurrence } \\
\text { of combination }\end{array}$} & \multicolumn{2}{|c|}{ Combination plus additional abnormality } & \multicolumn{2}{|c|}{ Upper bound of expected occurrence } \\
\hline & & & $\begin{array}{c}\text { Observed } \\
\text { occurrence }\end{array}$ & $\begin{array}{l}\text { Expected } \\
\text { occurrence }\end{array}$ & $\begin{array}{l}95 \% \text { confidence } \\
\text { limit }\end{array}$ & $\begin{array}{c}99 \% \text { confidence } \\
\text { limit }\end{array}$ \\
\hline $\begin{array}{l}\text { HA } \\
\text { GL } \\
\text { NF } \\
\text { HA }\end{array}$ & $\begin{array}{l}\text { HA } \cdot \mathbf{N F} \\
\text { HA } \cdot \text { GL } \\
\text { HA } \cdot \text { GL } \cdot \mathbf{N F} \\
\text { ADG } \cdot \mathbf{G L} \\
\mathbf{H A} \cdot \mathbf{N F} \\
\mathbf{H A} \cdot \mathbf{G L} \\
\mathbf{G L} \cdot \mathbf{N F}\end{array}$ & $\begin{array}{l}30 \\
41 \\
23 \\
25 \\
30 \\
41 \\
26\end{array}$ & $\begin{array}{r}9 \\
14 \\
8 \\
14 \\
23 \\
23 \\
23\end{array}$ & $\begin{array}{r}6 \cdot 2 \\
8 \cdot 5 \\
4 \cdot 8 \\
9 \cdot 6 \\
9 \cdot 4 \\
9 \cdot 4 \\
10 \cdot 0\end{array}$ & $\begin{array}{l}13 \cdot 1 \\
16 \cdot 3 \\
11 \cdot 3 \\
17 \cdot 7 \\
17 \cdot 5 \\
17 \cdot 2 \\
18 \cdot 3\end{array}$ & $\begin{array}{l}15 \cdot 6 \\
18 \cdot 8 \\
13 \cdot 5 \\
20 \cdot 2 \\
20 \cdot 1 \\
19 \cdot 7 \\
20 \cdot 4\end{array}$ \\
\hline
\end{tabular}

Expected occurrence $=\left(\begin{array}{l}\text { fraction of entire } \\ \text { study population } \\ \text { with 'additional } \\ \text { abnormality' }\end{array}\right)\left(\begin{array}{l}\text { observed number of cases with } \\ \text { the combination of abnormalities } \\ \text { chosen without regard to } \\ \text { 'additional abnormality' }\end{array}\right)$

the expected occurrence of these combinations are compared in Table 2. The occurrences of ADG with $\mathrm{HA}$, and with NF were seen no more frequently than may be expected on the basis of independence of morphological abnormalities. The occurrence of the combination of ADG with GL, however, exceeded the $99 \%$ confidence limit of the occurrence expected on the basis of independence of each of these abnormalities. Also exceeding the $99 \%$ confidence limit of the expected occurrence were HA - NF, HA - GL and NF. GL. Since each of these three subsets, HA.NF (30 infants), HA.GL (41 infants) and NF. GL (26 infants) included the 23 infants with $\mathbf{H A} \cdot \mathbf{G L} \cdot \mathbf{N F}$, a separate procedure was carried out to evaluate the occurrence of $\mathrm{HA} \cdot \overline{\mathrm{GL}} \cdot \mathrm{NF}, \mathrm{HA} \cdot \mathrm{GL} \cdot \overline{\mathrm{NF}}$, and $\overline{\mathrm{HA}} \cdot \mathrm{GL} \cdot \mathrm{NF}$. This included a calculation of the expected occurrence of two component combinations in a population devoid of the third abnormality and a comparison of this expected occurrence with the observed occurrence (Table 3). The observed occurrence of HA $\cdot \overline{\mathrm{GL}} \cdot \mathrm{NF}$ and $\overline{\mathrm{HA}} \cdot \mathrm{GL} \cdot \mathrm{NF}$ approximated the expected. The observed occurrence of $\mathrm{HA} \cdot \mathrm{GL} \cdot \overline{\mathrm{NF}}$, however, exceeded the $95 \%$ confidence limit of the expected occurrence.

The expected occurrence of three and four component combinations of abnormalities were calculated on the basis of random occurrence of one abnormality in populations in which other abnormalities may be clustered. These expected occurrences were compared with the observed occurrences (Table 4). ADG were not seen to occur in any subset of three abnormalities significantly more than expected. On the other hand, the observed number of infants with HA.GL·NF significantly exceeded the expected number.

\section{DISCUSSION}

In preparation for epidemiological studies of PTL it appeared necessary to determine whether the morphological components of PTL as originall $+\hat{N}$ described, represented a single entity or a group of entities. Judgments about the relationships betwee components of a morphological 'syndrome' may be based on studies of (1) the frequency of occurrence of groups of components-that is, clustering, (29 temporal patterns of the occurrence of components or groups of components, (3) association of com ponents or groups of components with risk factors, ? and (4) associations of components or groups of components with clinical features. This report is concerned only with a study of the clustering of components.

Such terms as 'analysis of attribute-cluster blocs' (Beyle, 1931), 'cluster analysis' (Tryon, 1939; Sokal and Sneath, 1963), and 'clustering method' (McQuitty, 1964) have been applied to methods using correlation coefficients. Although the method employed in this study may be considered a different type of cluster analysis, applying the name cluster analysis to this method may be confusing. The principles of Boolean algebra, upon which this method is based, were first formulated more than a century ago (Boole, 1854). Only recently, however, has their value to clinical medicine been appreciated (Feinstein, 1964; Black, 1970).

This study has demonstrated that the four morphological abnormalities of the original description of PTL occur in three clusters: ADG.GL, HA.GL (in a population devoid of NF), and $\mathrm{HA} \cdot \mathrm{GL} \cdot \mathrm{NF}$. The latter two clusters are distinct yet measure a greater degree of association of HA. GL than either 
one alone. Because they share the common feature of $\mathbf{H A} \cdot \mathrm{GL}$, they may be grouped together. What was previously considered PTL may therefore be divided into two entities, one characterized by ADG - GL and the other by HA.GL. Since HA do not cluster with ADG. GL nor ADG with HA.GL, the two entities do not occur together significantly more than would be expected on the basis of the independent occurrence of each.

Splitting something into two parts presents the problem of restricting the original name to only one of the two parts, or else eliminating it completely and starting with two new names. In view of the strength of association of HA and GL in two separate clusters, it would appear appropriate at this time to limit the name PTL to the presence of both HA and GL in neonatal telencephalic white matter. This is done with two reservations in mind. The first is the possibility that HA.GL $\cdot \mathrm{NF}$ and $\mathrm{HA} \cdot \mathrm{GL} \cdot \overline{\mathrm{NF}}$ are two separate entities as defined by temporal patterns, risk factors and/or clinical correlates, even though they share the feature of HA.GL. The second reservation reflects the limitation of the techniques employed in this study. The simple analysis for clustering used here can demonstrate an association between two or more characteristics. The evaluation of the occurrence of an isolated characteristic is beyond its province. Thus, there is the possibility that HA alone or GL alone may be shown by other evaluation procedures to be adequate criteria of PTL.

Restricting the name PTL to HA.GL leaves ADG.GL without a name. Until such time as there is reason to do otherwise, the entity characterized by ADG - GL in neonatal telencephalic white matter will be called simply 'ADG.GL'.

The finding that $\mathrm{GL}$ is common to all three clusters raises the question of the significance of GL. Two extreme possibilities may be considered. One group of possibilities is that GL are the most sensitive (or reproducible) indicators of neonatal white matter injury. A corollary of the 'sensitivity' hypothesis is that GL become manifest before HA or ADG. The other possibility is that GL are a non-specific response to insults that may differ quantitatively or qualitatively. These two possibilities are not mutually exclusive. They are, however, analogous to the sensitivity/selectivity function of screening tests (Thorner and Remein, 1961).

In every single comparison made in all four tables, the observed occurrence of combinations of abnormalities exceeded the expected. This suggests that all four abnormalities are associated to some extent even though the excess in many instances does not reach significance at the customary $5 \%$ level in this small sample.

This study was supported in part by funds provided by the United Cerebral Palsy Research and Educational Foundation (R-224-69), by the Program-Project Grant No. NSI-EP, 1P01 NS 09704-01 NSPA, HD, NINDS, and the Children's Hospital Medical Center Mental Retardation and Human Development Research Program (HD 03-0773), NICHD. The authors are indebted to Miss Denise Lortie for manuscript preparation.

\section{REFERENCES}

Beyle, H. C. (1931). Identification and Analysis of AttributeCluster Blocs. University of Chicago Press: Chicago.

Boole, G. (1854). An Investigation of the Laws of Thought. Walton and Maberly: London. (Reprinted in 1951 by Dover: New York).

Black, D. A. K. (1970). Diagnosis in renal disease-II. Brit. med. J., 2, 387-389.

Diem, K. (ed.) (1962). Documenta Geigy Scientific Tables. Sixth ed., pp. 99-101. Geigy Pharmaceuticals: Ardsley, New York.

Feinstein, A. R. (1964). Scientific methodology in clinical medicine. 1. Introduction, principles and concepts. $A n n$. int. Med., 61, 564-579, and 2. Classification of human disease by clinical behaviour. Ann. int. Med., 61, 757-781.

Gilles, F. H., and Murphy, S. F. (1969). Perinatal telencephalic leucoencephalopathy. J. Neurol. Neurosurg. Psychiat., 32, 404-413.

McQuitty, L. L. (1964). Capabilities and improvements of linkage analysis as a clustering method. Educ. psychol. Measur., 24, 441-456.

Schor, S. (1968). Fundamentals of Biostatistics, pp. 93-99. Putnam: New York.

Sokal, R. R., and Sneath, P. H. A. (1963). Principles of Numerical Taxonomy. Freeman: San Francisco.

Thorner, R. M., and Remein, Q. R. (1961). Principles and Procedures in the Evaluation of Screening for Disease. (Public Health Monograph no. 67). Govt. Printing Office: Washington, D.C.

Tryon, R. C. (1939). Cluster Analysis. Edwards: Michigan. 